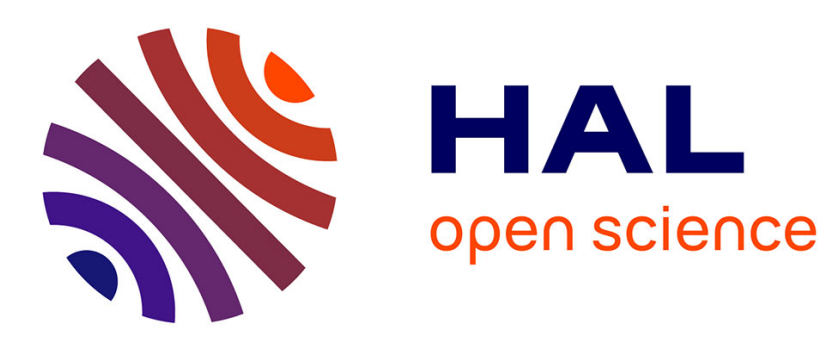

\title{
Brillouin scattering in SA and SB phases of butyloxy-benzilidene octylaniline
}

\author{
M. Čopič, M. Zgonik, B.B. Lavrencic
}

\section{To cite this version:}

M. Čopič, M. Zgonik, B.B. Lavrencic. Brillouin scattering in SA and SB phases of butyloxy-benzilidene octylaniline. Journal de Physique Lettres, 1981, 42 (17), pp.405-407. 10.1051/jphyslet:019810042017040500 . jpa-00231958

\section{HAL Id: jpa-00231958 https://hal.science/jpa-00231958}

Submitted on 1 Jan 1981

HAL is a multi-disciplinary open access archive for the deposit and dissemination of scientific research documents, whether they are published or not. The documents may come from teaching and research institutions in France or abroad, or from public or private research centers.
L'archive ouverte pluridisciplinaire HAL, est destinée au dépôt et à la diffusion de documents scientifiques de niveau recherche, publiés ou non, émanant des établissements d'enseignement et de recherche français ou étrangers, des laboratoires publics ou privés. 


\title{
Brillouin scattering in $S_{A}$ and $S_{B}$ phases of butyloxy-benzilidene octylaniline
}

\author{
M. Čopič, M. Zgonik and B. B. Lavrenčič \\ J. Stefan Institute and Department of Physics, University of Ljubljana, 61001 Ljubljana, Yugoslavia
}

(Reçu le 2 septembre 1980, révisé le 7 juillet 1981, accepté le 10 juillet 1981)

\begin{abstract}
Résumé. - Nous avons mesuré l'anisotropie des ondes sonores quasilongitudinales dans les phases $S_{A}$ et $S_{B}$ de $\mathrm{n}$-butyloxy-benzilidène n-octylaniline. Les données expérimentales permettent de déterminer les grandeurs des trois constantes d'élasticité. Bien que la valeur de la constante d'élasticité correspondante aux ondes de cisaillement soit relativement très élevée, la propagation d'une telle onde n'a pas été observée.
\end{abstract}

Abstract. - The anisotropy of the quasilongitudinal sound waves in the $S_{A}$ and $S_{B}$ phases of $n$-butyloxy-benzilidene $n$-octylaniline was measured. From the data, three elastic constants were determined. A propagating shear wave was not observed in spite of a relatively large value of the relevant elastic constant.

Smectic liquid crystals are characterized by both orientational and partial translational ordering. This leads to more complicated first order elastic properties compared to ordinary liquids or nematic 1.c., for example anisotropy of the longitudinal sound velocity and propagating shear acoustic waves. Such waves are predicted by the phenomenological elastohydrodynamic theory [1, 2] and have been observed by Brillouin scattering in the smectic $A$ and $B$ phases of $\beta$-methylbutyl $\mathrm{p}[(\mathrm{p}$-methoxy-benzilidene) amino $]$ cinnamate [3]. Ultrasonic and Brillouin scattering investigations in the smectic A and B phases [4-8] show the expected angular dependence of the velocity of longitudinal sound waves; shear waves, however have not been observed. We present here the results of Brillouin scattering in the smectic A and B phases of $\mathrm{n}$-butyloxy-benzilidene $\mathrm{n}$-octylaniline (in short BOBOA).

The experiment was performed on monodomain samples which were obtained by placing BOBOA between two lecithin-treated glass surfaces separated by $180 \mu \mathrm{m}$ and heated above the nematic isotropic transition $\left(79.0^{\circ} \mathrm{C}\right)$. Upon slow cooling we obtained successively monodomain samples in the nematic phase $\left(79^{\circ} \mathrm{C}>T>63^{\circ} \mathrm{C}\right)$, smectic A phase $\left(63{ }^{\circ} \mathrm{C}>T>48{ }^{\circ} \mathrm{C}\right)$ and smectic $\mathrm{B}$ phase $\left(48^{\circ} \mathrm{C}>T>30^{\circ} \mathrm{C}\right)$. The smectic B phase could be supercooled to room temperature, where it would crystallize in about a day if left undisturbed. The orientation was confirmed by observation under polarizing microscope, which also helped to determine the transition temperatures. Temperature control of the sample was achieved by placing the sample in a scattering cell, filled with paraffin oil and stabilized to within $0.1^{\circ} \mathrm{C}$.

In the scattering experiment a beam of linearly polarized light with wavelength $514.5 \mathrm{~nm}$ from a single mode Ar-ion laser was focused on the sample. Incident power was kept at about $100 \mathrm{~mW}$, which insured sufficiently low heating of the scattering region. This was checked by reducing the incident power by a factor of 3 after which we obtained the same results within the experimental error. The light scattered through an external scattering angle of $\pi / 2$ was analysed using a triple-pass flat Fabry-Perot interferometer. The internal scattering angle had to be corrected for the refraction at the sample boundary. Therefore we measured the ordinary refractive index of BOBOA with an Abbe refractometer illuminated with laser light and found it to be 1.501 at $30^{\circ} \mathrm{C}$ and 1.498 at $55^{\circ} \mathrm{C}$. Its temperature variation in the smectic $A$ and $B$ phases is not significant for the analysis of the Brillouin scattering data. Since we were able to observe a Brillouin peak only with both the incoming and scattered light polarized as ordinary waves, extraordinary index of refraction was not needed.

In the VV scattering geometry, that is with both the incoming and scattered waves polarized as ordinary waves, we could easily observe the Brillouin doublet corresponding to the quasilongitudinal sound. Rotation of the sample enabled us to measure the angular dependence of the sound velocity. Two typical curves are shown in figure 1. 


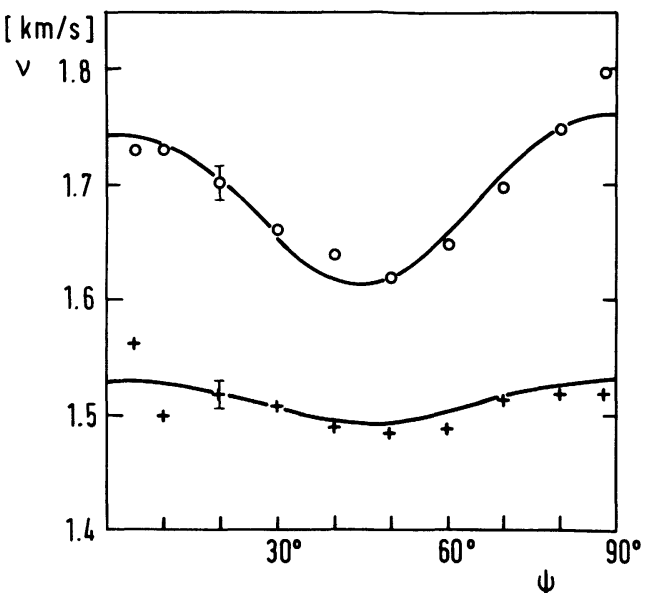

Fig. 1. - Angular dependence of the longitudinal sound velocity. (O) smectic B $\left(T=32^{\circ} \mathrm{C}\right) ;(+)$ smectic $\mathrm{A}\left(T=56^{\circ} \mathrm{C}\right)$.
The data were analysed in terms of simple elastohydrodynamic theory of the smectic phases. The elastic energy of a smectic A system can be written in the form [1]

$$
\begin{aligned}
W=\frac{1}{2} A \theta^{2}+C \theta \frac{\partial u}{\partial z}+\frac{1}{2} B\left(\frac{\partial u}{\partial z}\right)^{2}+ \\
+\frac{1}{2} K\left(\frac{\partial^{2} u}{\partial x^{2}}+\frac{\partial^{2} u}{\partial y^{2}}\right)^{2}
\end{aligned}
$$

where $\theta$ is the relative change of density and $u$ is the displacement of smectic layers. In the smectic B phase one should add terms describing shear deformations in the plane of the layers. As these are not important for the present experiment, we will omit them.

Expression (1) gives two propagating sound waves with the velocities

$$
\begin{aligned}
& v_{1}^{2}=\frac{1}{2 \rho}\left[A+(B+2 C) \cos ^{2} \psi+\sqrt{\left.\left[A+(B+2 C) \cos ^{2} \psi\right]^{2}-\left(A B-C^{2}\right) \cos ^{2} \psi \sin ^{2} \psi\right]}\right. \\
& v_{2}^{2}=\frac{1}{2 \rho}\left[A+(B+2 C) \cos ^{2} \psi-\sqrt{\left.\left[A+(B+2 C) \cos ^{2} \psi\right]^{2}-\left(A B-C^{2}\right) \cos ^{2} \psi \sin ^{2} \psi\right]}\right.
\end{aligned}
$$

where $\psi$ is the angle between the direction of propagation and the normal to the smectic layers. The first solution represents a nearly longitudinal sound wave, whereas the second represents a shear like wave, which does not propagate in the directions $\psi=0$ and $\psi=\pi / 2$ and has occasionally been named second sound due to a furmal analogy to superfluid helium [1].

The first three terms of the elastic energy can also be written in the form, appropriate for hexagonal crystals except that $C_{11}=C_{12}$ and $C_{44}=0$ [3] :

$$
\begin{aligned}
W=\frac{1}{2} C_{11}\left(X_{1}\right. & \left.+X_{2}\right)^{2}+ \\
& +C_{13} X_{3}\left(X_{1}+X_{3}\right)+\frac{1}{2} C_{33} X_{3}^{2}
\end{aligned}
$$

where $X_{i}$ are the components of the deformation tensor. The constants $A, B$ and $C$ can then be expressed in terms of the elastic constants :

$A=C_{11} ; B=C_{11}+C_{33}-2 C_{13} ; C=C_{13}-C_{11}$.

The data for each temperature were Fourier analysed and by comparing the Fourier coefficients with the series expansion of the expression $(2 a)$, the elastic coefficients $A, B$ and $C$ were easily obtained. These values are contained in figure 2 .

The results are similar to those obtained previously [3-7]. In the smectic A phase both coefficients $A$ and $C$ extrapolate approximately linearly to zero as the smectic A-nematic transition is approached. The interesting feature to note is that both in the $S_{A}$ and $S_{B}$ phase $B=-2 C$ within the experimental error.

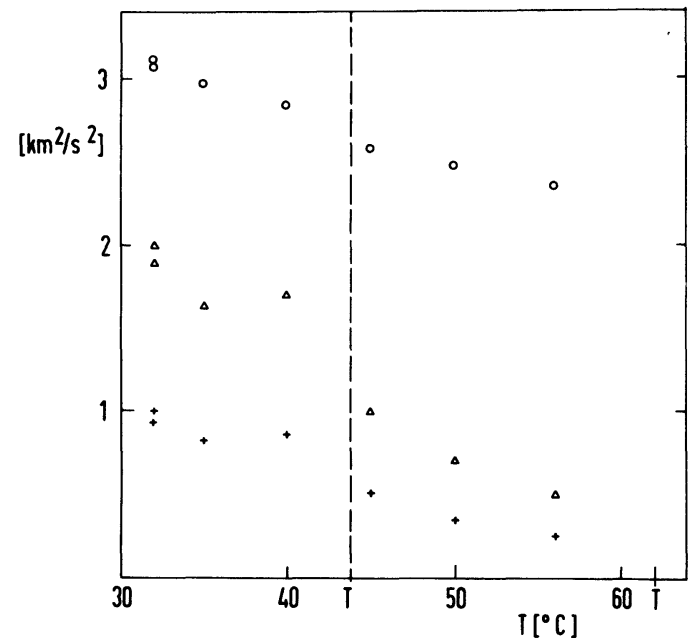

Fig. 2. - Temperature dependence of $A / \rho(O), B / \rho(\triangle)$ and $C / \rho(+)$ in the smectic $\mathrm{A}$ and $\mathrm{B}$ phases of BOBOA.

This gives in terms of the elastic tensor $C_{11}-C_{33}<0.01$. Ultrasonic measurements in other systems [4-7] indicate considerably higher values for this difference.

In spite of the very rough temperature scale there seems to be some indication for a jump in all elastic coefficients at the $S_{A}-S_{B}$ transition. Additional data in the vicinity of the transition are needed to confirm this.

We have also searched for a propagating shearlike wave, which should best be observable in the $\mathrm{HH}$ scattering geometry. The expression $A B-C^{2}$, which governs the velocity of such wave, is relatively large, so that the corresponding Brillouin shift should be 
of the order of $0.05 \mathrm{~cm}^{-1}$ when $\psi \sim 30^{\circ} \mathrm{C}$. Yet we have not found any resolved Brillouin peak in the $\mathrm{HH}$ spectra. However, we observed a diffuse wing of the central scattering component, the width of which we estimated to be about $0.05 \mathrm{~cm}^{-1}$. Due to very intense elastic component it was not possible to make a real measurement.

It seems then, that in BOBOA in both the $\mathrm{S}_{\mathrm{A}}$ and $S_{B}$ phases the shear-like wave is overdamped. A possible damping mechanism can be a coupling with intramolecular degrees of freedom, mainly the motions of the aliphatic chains. The constant $B$ measures layer compressibility and should therefore strongly depend on the properties of the chains. Such hypothesis is supported by the fact that propagating shear waves were observed in a substance that has relatively short tails (1 and 4 carbon atoms [3]), whereas our sample had considerably longer ones (4 and 8 carbon atoms). Unfortunately, at present we do not have at our disposal suitable samples to test this hypothesis.

To summarize, we have measured the anisotropy of the longitudinal sound waves in the $S_{A}$ and $S_{B}$ phases of BOBOA and have obtained three first order elastic constants. More measurement are needed to examine the behaviour of these constants near the smectic $A$ to $B$ and $S_{A}$ to nematic transitions. The shear-like wave (second sound) seems to be overdamped due to the rather long aliphatic chains. This must be examined more thoroughly.

\section{References}

[1] De Gennes, P. G., The Physics of Liquid Crystals, (Oxford University Press) 1974.

[2] Martin, P., Parodi, O. and Pershan, P. S., Phys. Rev. A 6 (1972) 2401.

[3] Liao, Y., Clark, N. and Pershan, P. S., Phys. Rev. Lett. 30 (1973) 639.

[4] LoRD, A. E., Phys. Rev. Lett. 29 (1972) 1366.
[5] Miyano, K. and Ketterson, J. B., Phys. Rev. Lett. 31 (1973) 1047.

[6] Miyano, K. and Ketterson, J. B., Phys. Rev. A 12 (1975) 615.

[7] Wergin, A., Krasser, W., STiller, H. H., Erischkom, C. G. B., Phys. Rev. A 20 (1979) 1120.

[8] Bradberry, G. W. and Vaughan, J. M., J. Phys. C 9 (1976) 3905 . 